\begin{tabular}{|c|c|c|}
\hline Case Reports in & \multicolumn{2}{|c|}{ Case Rep Gastroenterol 2014;8:156-161 } \\
\hline Gastroenterology & $\begin{array}{l}\text { DOI: 10.1159/000363176 } \\
\text { Publisned onlIne: IVay 8, } 2014\end{array}$ & $\begin{array}{l}\text { (C) } 2014 \text { S. Karger AG, Basel } \\
1662-0631 / 14 / 0082-0156 \$ 39.50 / 0 \\
\text { www.karger.com/crg }\end{array}$ \\
\hline & \multicolumn{2}{|c|}{$\begin{array}{l}\text { This is an Open Access article licensed under the terms of the Creative Common } \\
\text { Attribution-NonCommercial } 3.0 \text { Unported license (CC BY-NC) (www.karger.com/OA } \\
\text { license), applicable to the online version of the article only. Distribution permitted for non } \\
\text { commercial purposes only. }\end{array}$} \\
\hline
\end{tabular}

\title{
Obturator Hernia with Ureteral Entrapment
}

\author{
Matteo Izzo Luca Regusci Fabrizio Fasolini \\ Department of Surgery, Ospedale Beata Vergine, Mendrisio, Switzerland
}

\section{Key Words}

Obturator hernia $\cdot$ Ureteral entrapment $\cdot$ Surgical technique

\begin{abstract}
Obturator hernia of the ureter is uncommon. Computed tomography of a 77-year-old woman with sudden-onset lower left abdominal pain and urinary symptoms showed an obturator hernia with ureteral entrapment. Obturator hernia is a diagnostic challenge because the hernial mass is very insidious. It should be suspected in emaciated, multiparous, elderly women presenting with unexplained pain in the groin, hip, thigh or knee. High levels of clinical suspicion of high-risk patients and recourse to investigation by computed tomography are important, as delay in diagnosis and treatment is associated with increased morbidity and mortality.

(c) 2014 S. Karger AG, Basel
\end{abstract}

\section{Introduction}

Obturator hernia is a rare pelvic hernia with a relatively high morbidity and mortality. It was first described by Ronsil in 1724 [1], with the nickname 'little old lady's hernia', as it affects this group due to atrophy and loss of the pre-peritoneal fat around the obturator vessels in the canal, predisposing to hernia formation. The incidence is $0.07-1 \%$ of all hernias [2] and it usually occurs in elderly emaciated women due to a wider pelvis and enlarged obturator canal.

Concerning anatomy, the obturator foramen is formed by the ramification of the ischium and the pubic bone; the foramen is partially closed by a musculoaponeurotic barrier composed by the obturator membrane by the obturator muscle. The obturator canal is approximately $0.2-0.5 \mathrm{~cm}$ wide and $2-3 \mathrm{~cm}$ long and inside of it we can find the obturator nerve, artery and vein [3]. Usually the hernia sac passes through the obturator foramen, following the way of the obturator nerves and muscles. 
Izzo et al.: Obturator Hernia with Ureteral Entrapment

From a clinical point of view, symptoms are often vague and non-specific [4] and because of this the diagnosis is very difficult. There is rarely a palpable mass as in other common abdominal wall hernias, and pain along the ipsilateral thigh, exacerbated by adduction of the thigh (Howship-Romberg sign), caused by compression of the obturator nerve by the hernia, is highly suggestive. We can also find urinary symptoms when the hernia causes compression or damage of the urinary tract. Radiological investigation is extremely important and computed tomography has a good accuracy in diagnosing this disease. It is important for detecting damage to the surrounding tissues and essential for planning surgical intervention [5].

Here we present an interesting case of an elderly woman who presented an obturator hernia with left ureteral entrapment.

\section{Case Report}

A 77-year old woman was admitted to the surgical ward with vomiting, weakness, constipation and lower left quadrant abdominal pain that radiated posteriorly since 4 days. Clinical examination showed a moderately suffering patient, generally unwell, with a temperature of $38.4^{\circ} \mathrm{C}$, a heart rate of 96 beats per minute, low volume and a blood pressure of $110 / 70 \mathrm{~mm}$ Hg. Local examination showed a soft abdomen, mildly distended, with tenderness on palpation of the left iliac fossa, but clinically she exhibited no masses and had clear hernial orifices. Laboratory examination revealed high levels of C-reactive protein and creatinine; urine exams showed leukocyturia and hematuria.

After physical examination we moved on to radiological evaluation: direct abdominal $\mathrm{X}$-ray images obtained in the standing position did not reveal dilated loops in the small intestines or gas fluid levels. Echography showed hydronephrosis (grade I) at the left kidney. We then decided to use more detailed radiological investigations to have a clearer view of the visceral organs. Computed tomography showed a small intestine loop completely herniated through the left obturator foramen and an entrapment of the homolateral ureter (fig. 1); in this way the ureter presented a altered course to the foramen. It was necessary to consult an urologist.

In an emergency procedure the first step was laying a pigtail by ureteropyelography. This procedure allowed anatomical relocation of the ureter, which was important for early resolution of hydronephrosis and also for prevention of surgical lesions during the operation (fig. 2). Afterwards the patient was adequately hydrated and renal function tests were repeated, which were normal. She was prescribed prophylactic antibiotic therapy. After surgical consultation, we decided to operate the patient after the restoration of normal renal function. We waited 6 weeks and used this time to restore renal function; after urological examination, the blood levels of renal function and ultrasound examination were normal.

In a second step, the patient underwent elective surgery. A navel-pubic incision was made. The peritoneum was opened and some visceral adhesions were removed. The sigmoid was isolated to the rectum and obtained by Toldt's plane. The left ureter was identified; it appeared swollen and inflamed with pigtail. Adhesions were present between the ureter and the iliac vessels to the left. We determined the ureter problem to be caused by the compression by hernia, by the adhesions and by the consequent inflammatory state. Left salpingooophorectomy was performed to improve surgical vision. Detachment of adhesions between the ureter and vascular structures was performed at the level of the sciatic foramen, where there were numerous adhesions. Was evaluated the weakness of the superior foramen and a polypropylene mesh was placed to reinforce the obturator foramen (fig. 3). The mesh rested 
Izzo et al.: Obturator Hernia with Ureteral Entrapment

on the external iliac and the internal iliac vessels, posterior to the broad ligament and the rectum, in the pre-sacral region. The peritoneum, transversalis fascia and aponeurosis were then closed using 2-0 Vicryl ${ }^{\mathrm{TM}}$. The patient was treated with broad-spectrum antibiotics and rational nutritional support, and careful monitoring of vital organs was done.

The postoperative period was uneventful. Normal intestinal transit was achieved on day 2 after surgery. On physical examination, abdominal pain on both superficial and deep palpation was not noticed; at auscultation peristalsis was physiological. The indices of inflammation and creatinine showed stabilization in laboratory tests. She was discharged after 5 days and remained well without any complications during subsequent outpatient followup.

\section{Discussion}

Obturator hernias are difficult to diagnose clinically as palpation of the mass is often impossible; it is a diagnostic challenge because the signs and symptoms are usually nonspecific. The cardinal clinical symptom is acute intestinal obstruction. The clinical course is usually manifested by acute small bowel obstruction and pain on the medial aspect of the thigh due to compression of the obturator nerve. In rare cases, as in ours, there may also be urinary symptoms caused by compression of the ureters and of the lower urinary tract. Recent literature has shown that early diagnosis of obturator hernia can be made with computed tomography of the abdomen and pelvis. Our case demonstrates that radiological findings are useful for evaluating the impairment of surrounding anatomical structures that could be compressed.

The only treatment for obturator hernia is surgery. There are a variety of operative approaches [6] including the inguinal, retropubic and transperitoneal approach. Typically, the abdominal approach via a low midline incision is most commonly favored, as it allows adequate exposure of the obturator ring as well as identification and resection of any adhesions. This method allows the surgeon to establish the diagnosis, avoid any obturator vessels, achieve better exposure of the obturator ring and facilitate bowel resection. Simple closure of the hernial defect with interrupted sutures or placement of a synthetic mesh are the preferred methods of herniorrhaphy as they are associated with the lowest complication rates.

Recently, laparoscopic surgery for obturator hernia became another alternative approach [7]. The literature on this type of solution of obturator hernias is quite sparse [8, 9], probably due to a combination of the rarity of these cases and the relatively recent emergence of laparoscopic hernia surgery. Laparoscopic repair has been shown to produce less postoperative pain, less surgery complications and shorter hospital stays. Laparoscopic operations are less traumatic and therefore might be more suitable for this type of patients.

Impairment of the urinary tract is not so frequent in the literature. Especially in this type of patients, hydronephrosis can lead to serious problems: kidney damage and infections occur, ultimately leading to a non-functioning kidney if not treated efficiently. The use of a stent, such as the pigtail in these cases, allows both a restore anatomical axis of the structure and protection of the ureter during surgical procedures.

In our case, the etiological evaluation of pyelonephritis was very important for the treatment of urological and surgical therapy; preservation of the ureter allowed us to remedy the obturator hernia. For this reason, the initial approach of urology was crucial before surgery. In our case, preoperative evaluation was essential to perform successful surgical repair. This surgical approach may be particularly useful when diagnostic incon- 
Izzo et al.: Obturator Hernia with Ureteral Entrapment

gruity exists on the exact type of hernia suspected following preoperative and radiological assessment. To provide additional support to weakened and damaged tissue we used a nonabsorbable mesh; this type of mesh is useful to provide permanent reinforcement to the repaired hernia [10].

\section{Conclusions}

Obturator hernia is rare, but it must be considered in the differential diagnosis of thin, elderly patients, especially females with intestinal symptoms associated with hydronephrosis. Involvement of the renal tract is very rare; in a first step is important to preserve these structures. Computed tomography imaging is required for early diagnosis. The role of clinical examination is limited as the signs are often non-specific. Surgery is successful in most cases, but a multidisciplinary approach is often required.

\section{References}

1 Ziegler DW, Rhoads JE Jr: Obturator hernia needs a laparotomy, not a diagnosis. Am J Surg 1995;170:67-68.

2 Mantoo SK, Mak K, Tan TJ: Obturator hernia: diagnosis and treatment in the modern era. Singapore Med J 2009;50:866-870.

3 Bergstein JM, Condon RE: Obturator hernia: current diagnosis and treatment. Surgery 1996;119:133-136.

4 Hsu CH, Wang CC, Jeng LB, Chen MF: Obturator hernia. Surg Gynecol Obstet 1988;167:217-222.

5 Chung CC, Mok CO, Kwong KH, Ng EKW, Lau WY, Li AKC: Obturator hernia revisited: a review of 12 cases in 7 years. J R Coll Surg Edinb 1997;42:82-84.

6 Nakayama T, Kobayashi S, Shiraishi K, Nishiumi T, Mori S, Isobe K, Furuta Y: Diagnosis and treatment of obturator hernia. Keio J Med 2002;51:129-132.

7 Deeba S, Purkayastha S, Darzi A, Zacharakis E: Obturator hernias: a review of the laparoscopic approach. J Minim Access Surg 2011;7:201-204.

8 Sze Li S, Kenneth Kher Ti V: Two different surgical approaches for strangulated obturator hernias. Malays J Med Sci 2012;19:69-72.

-9 Kohi S, Sato N, Mori Y, Uehara T, Tamura T, Minagawa N, Torigoe T, Shibao K, Higure A, Yamaguchi K: A review of 13 cases of obturator hernia. J UOEH 2013;35:273-277.

10 Luijendijk RW, Hop WC, van den Tol MP, de Lange DC, Braaksma MM, Ijzermans JN, Boelhouwer RU, de Vries BC, Salu MK, Wereldsma JC, Bruijninckx CM, Jeekel J: A comparison of suture repair with mesh repair for incisional hernia. N Engl J Med 2000;13:392-398. 


\begin{tabular}{|c|c|c|}
\hline \multirow{2}{*}{$\begin{array}{l}\text { Case Reports in } \\
\text { Gastroenterology }\end{array}$} & \multicolumn{2}{|c|}{ Case Rep Gastroenterol 2014;8:156-161 } \\
\hline & DOI: $10.1159 / 000363176$ & $\begin{array}{l}\text { (c) } 2014 \text { S. Karger AG, Base } \\
\text { www.karger.com/crg }\end{array}$ \\
\hline
\end{tabular}

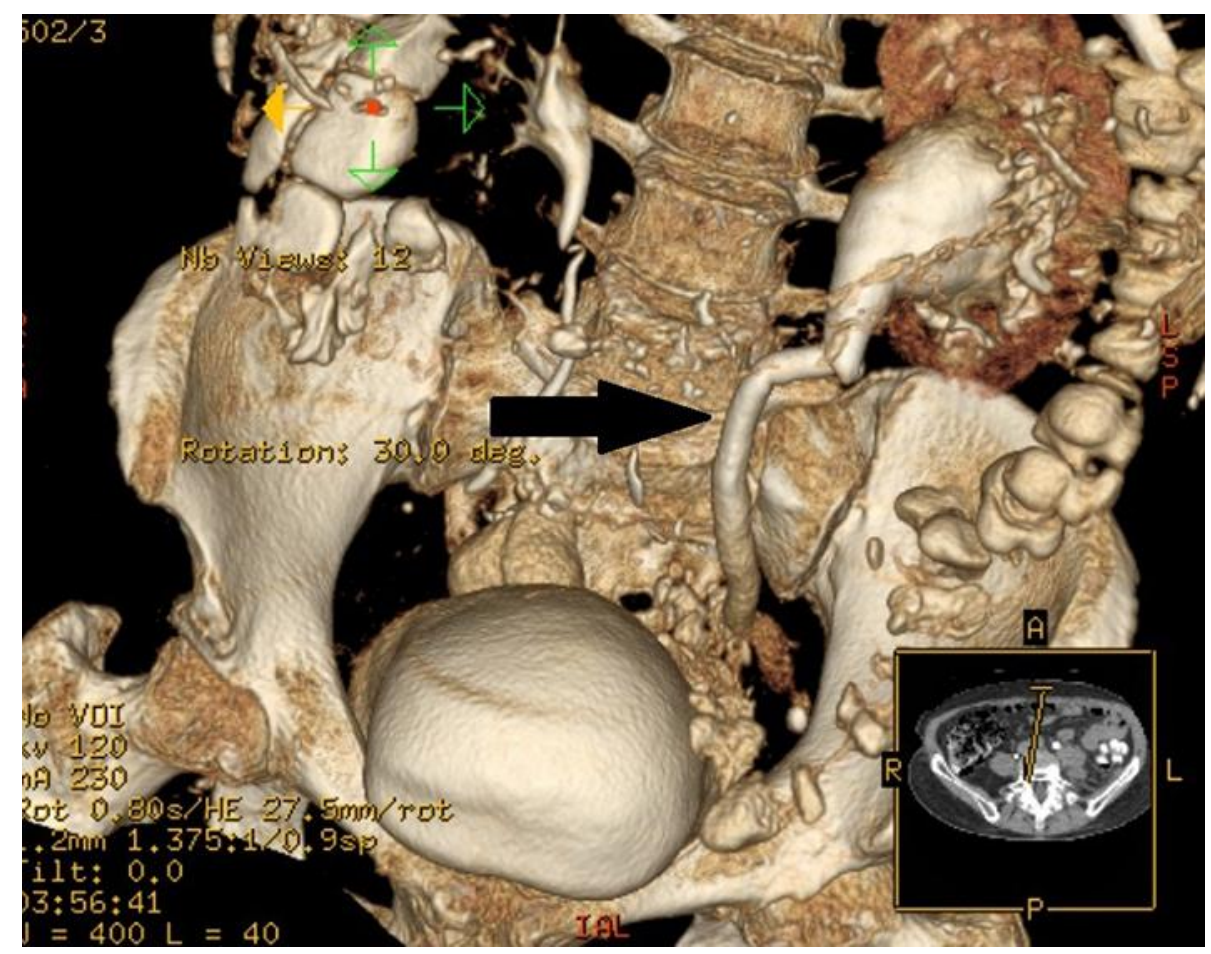

Fig. 1. Reconstruction of the images shows hydronephrosis in the left kidney and ureter obstruction distally.

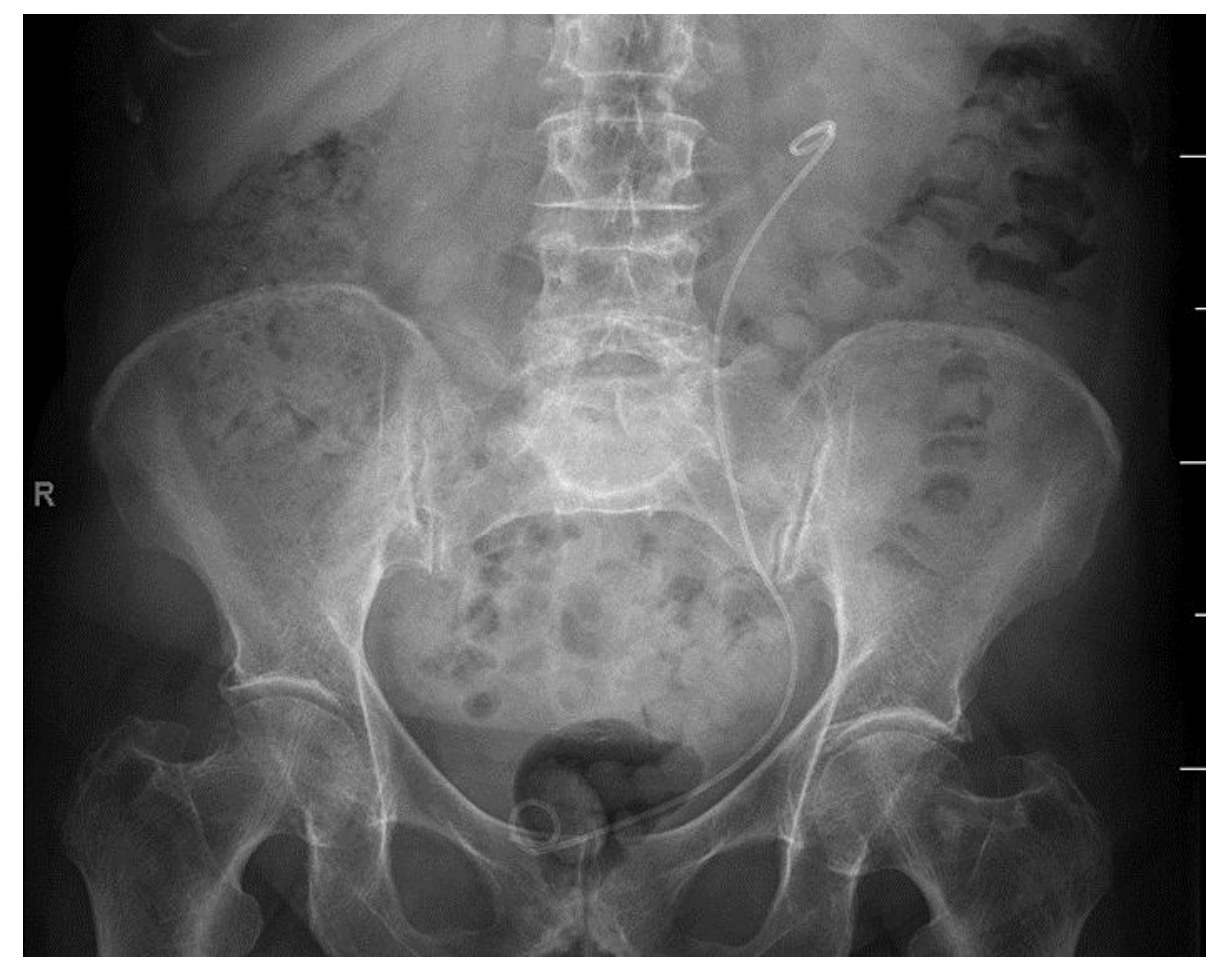

Fig. 2. The pigtail placed into the left kidney. 


\begin{tabular}{ll|l} 
Case Reports in & \multicolumn{2}{l}{ Case Rep Gastroenterol 2014;8:156-161 } \\
\cline { 2 - 3 } Gastroenterology & DOI: 10.1159/000363176 & $\begin{array}{l}\text { ○ 2014 S. Karger AG, Basel } \\
\text { www.karger.com/crg }\end{array}$ \\
\cline { 2 - 2 } & Izzo et al.: Obturator Hernia with Ureteral Entrapment
\end{tabular}

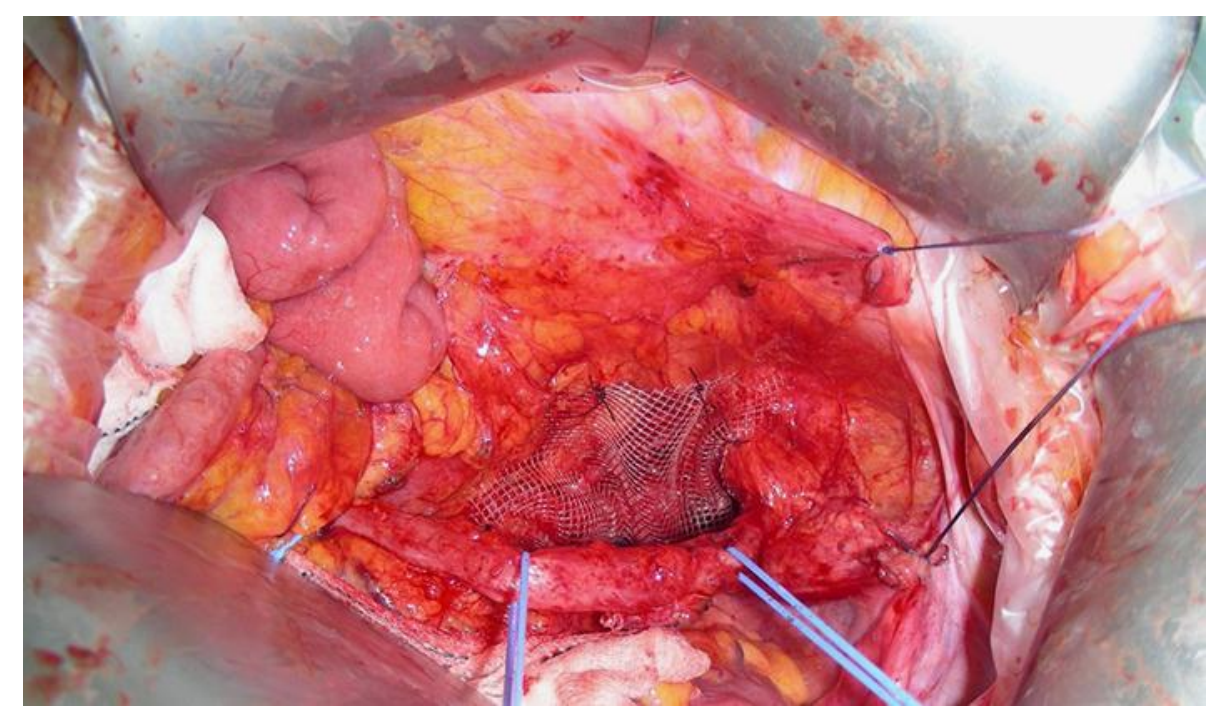

Fig. 3. The polypropylene mesh placed in the obturator foramen. 